\title{
Integration of Telecommunication Technologies into Agricultural Market Information Systems: a comparative analysis of Uganda and Malawi
}

\section{Leonard Chalemba ${ }^{1}$}

\section{N F O}

Received 31 Mar. 2016

Accepted 15 Jul. 2016

Available on-line 15. Aug. 2016

Responsible Editor: M. Herdon

\section{Keywords:}

agricultural market information systems, information and communication technology, Uganda, Malawi, and smallholder farmers.

\begin{abstract}
$\underline{\text { A B S T R A C T }}$
The paper presents a comparison of the potential of integrating telecommunication technologies into the agricultural market information systems operating in Uganda and Malawi. Data on economic indicators related to telecommunications services provided by the statistics division of the United Nations were used for the comparative analysis. The review reveals that both Uganda and Malawi need significant improvement in the provision of information and communication technology (ICT) facilities to low-income smallholder farmers for them to fully utilise the services offered by ICT-based market information services. Specific areas for improvement include increasing mobile phone subscriptions and Internet access, and promoting private sector participation. Recommendations drawn from this analysis do not only apply to Malawi and Uganda but also to other countries in Sub-Saharan Africa.
\end{abstract}

\section{Introduction}

Nowadays, any meaningful agricultural market information system employs information and communication technologies for effective delivery of its services. An agricultural market information system is herein understood as any organised way of collecting, storing and disseminating market information such as commodity prices which can help stakeholders such as farmers and traders in the agricultural value chain to make informed decisions when participating in agricultural trading processes. Common information and communication technology (ICT) platforms include the radio, television, the short message service (SMS) of mobile telephony, e-mail, and Internet websites. A market information system (MIS) can also use non-ICT platforms such as newsletters and newspapers for service delivery.

This paper presents a review of the comparison of the potential of using ICT-based agricultural market information systems in the two Sub-Saharan African countries of Uganda and Malawi. The aim of the review is to determine a set of recommendations, for policy makers, on the possible ways of improving service delivery of agricultural MIS initiatives in Uganda and Malawi, and also in the rest of Sub-Saharan Africa. The analysis is focused on agricultural market information systems associated with domestic agricultural trade; however, some of the reviewed systems are involved in both domestic and international agricultural trade. Main sources of information used for the preparation of this paper are published articles in journals and as conference proceedings, progress report documents by both local and international organisations, government documents, published books, Internet websites, and observations by the author in the case of Malawi.

Most countries in Sub-Saharan Africa had strict control, usually through state-owned enterprises, over the marketing of agricultural commodities and trading of farm inputs from the time of independence from colonial powers up to 1970s. The promotion of economic reforms by the World Bank, International Monetary Fund (IMF) and international donor agencies in the period between 1980s and 1990s compelled most of the Sub-Saharan African countries to adopt agricultural market liberalisation policies, which were part of the economic reforms (Kherallah, et al., 2000; Magesa, et al. 2014). Soon after implementing the agricultural market liberalisation policies, policy makers realised that poor smallholder farmers were likely to be exploited by traders since the market environment was not transparent enough to stakeholders (Tollens, 2006). As a way of addressing this concern,

\footnotetext{
${ }^{1}$ chalembaleo@yahoo.com
} 
agricultural market information systems were introduced; initially by international donor agencies and later by governments and the private sector. Through such market systems smallholders were able to access current market information on commodity prices, which helped them in making informed decisions in bargaining processes (USAID, 2013).

Uganda is one of the Sub-Saharan African countries where the establishment of agricultural market information systems was promoted by international donor agencies, which worked mostly in partnership with the government. Two of the donor agencies which worked with the government in the provision of agricultural market information in the 1990s were Food and Agriculture Organisation (FAO) and United States Agency for International Development (USAID) (Robbins, 2000). Uganda has many agricultural MIS initiatives supported by both local and international Non-Governmental Organisations (NGOs). Some of the locally-based NGOs that promote agricultural MIS projects are Catholic Relief Service (CRS) and Agribusiness Development Centre (ADC) (Robbins, 2000).

Another Sub-Saharan African country which benefitted from the support of international donor agencies in the establishment of agricultural market information systems is Malawi. One of the successful agricultural MIS initiatives in Malawi is a radio-based agricultural MIS project financed by Agriculture Commodity Exchange (ACE) for Africa. Malawi also has a well-functioning agricultural MIS project based on the short message service (SMS) of mobile telephony, and funded by Agribusiness Systems International (ASI) (ASI, 2015; DAES, 2013).

A comparison of the potential of integrating telecommunication technologies into agricultural MIS initiatives in Uganda and Malawi carried out in this review shows that both Uganda and Malawi do not have adequate ICT facilities for them to fully exploit the benefits which come with ICT-based MIS initiatives. However, the potential of providing such services is slightly higher for Uganda than it is for Malawi since Uganda has slightly higher mobile phone subscription rates and Internet user rates than Malawi. The review used the data on economic indicators related to telecommunications services provided by the statistics division of the United Nations (UNSD, 2016). The final product of this review appears as recommendations at the end of this paper. The recommendations focus on two main areas: the need to provide more ICT facilities to support agricultural MIS initiatives, and increasing participation of the private sector for provision of self-financing agricultural MIS projects which are sustainable economically.

\section{Background on Agricultural Market Information Systems}

From the time of political independence up to 1970s, most countries in Sub-Saharan Africa had strict control, mostly through state-owned enterprises, over the marketing of agricultural commodities and trading of farm inputs (Kherallah, et al., 2000; Magesa, et al. 2014). In some countries such policies were inherited from the colonial powers. The policy makers of such governments that controlled agricultural trade were generally of the opinion that private traders of staple food crops such as maize were exploitative, and therefore it was not economically, socially, and politically prudent to trust them with the important task of feeding nations (Kherallah, et al., 2000).

The policies of strict control over the agricultural sector and on the other sectors of national economies pursued by the Sub-Saharan African governments in the 19960s and 70s began to show negative impacts, mostly economic stagnation, on the national economies (Nyairo, 2011; Alderman \& Shively, 1996). When the affected governments approached the World Bank, IMF and other international money lending institutions for financial assistance, they were compelled by these organisations to accept and implement agricultural market liberalisation policies as conditions for getting financial assistance. These policies were part of economic reforms, known as structural adjustment programs (SAP), promoted by international money lending organisations such as the World Bank ; in Sub-Saharan Africa such reforms took place in the 1980s and early 1990s (Kherallah, et al., 2000).

Implementation of the agricultural market liberalisation policies promoted participation of the private sector. Soon after the implementation, policy makers realised that the market liberalisation policies had a serious weakness of rendering poor smallholder farmers vulnerable to exploitation by 
private traders since the market environment was not transparent enough to the stakeholders. In particular, smallholder farmers lacked current market information to help them in making informed decisions during bargaining processes. In fact, a study conducted by Robbins (2000-b) on market information systems in Botswana, Ethiopia, Ghana, and Zimbabwe reveals that private traders were encouraged to collude and exploit both producers and consumers by a combination of inadequate legal control and lack of availability of current market information to stakeholders in the agricultural value chain. To address the danger of exploitation of farmers (especially low-income smallholder farmers) by private traders, policy makers established agricultural market information systems as a way of making agricultural markets more transparent to stakeholders (Jayne \& Jones 1997; USAID, 2013). Agricultural market information systems were not only established in Sub-Saharan Africa but also in other developing countries all over the world (CTA, 2000; Islam \& Gronlund, 2010).

In Sub-Saharan Africa, the introduction of well-functioning agricultural market information systems was initiated and funded by international donor agencies such as USAID (USAID, 2013). Uganda is one of the countries in Sub-Saharan Africa which benefitted from agricultural market information systems promoted by international donor agencies. In the early 1990s, the government of Uganda established a market information service with financial assistance from FAO. Later (in 1993), funding of this government-run market information service was taken over by USAID (Robbins, 2000). The market information service offered by the government came to an end in 1999, but Ugandans continued to have access to reliable market information mostly provided by an association of farmers called Uganda National Farmer's Association (UNFA) which was funded by Danish International Development Agency (DANIDA). Ugandans did not only have market information from UNFA but also from many other agricultural MIS projects financed by both local and international donor agencies. Examples of such locally-based donor organisations are Catholic Relief Service (CRS) and Agribusiness Development Centre (ADC), while Agricultural Co-operative Development International (ACDI) and Irish Foundation for Co-operative Development (IFCD) are examples of international donor agencies which helped to fund agricultural MIS projects in Uganda apart from DANIDA (Robbins, 2000). Some of these donor agencies (both local and International ones) are still financially supporting many agricultural MIS initiatives that are currently in operation in Uganda.

In Malawi, just like in many other Sub-Saharan countries, the establishment of well-defined agricultural market information systems was initiated about a decade or two ago by international donor agencies especially those linked to USAID. Market information was only provided by the government through the Department of Agriculture Extension Services before the establishment of donor-initiated market information systems. The market services offered by the Deparment mainly targeted smallholder farmers, and constituted a very small component of the overall agricultural extension services. The government-run agricultural MIS has been in operation for three to four decades now, and is still operating; however, it is not as effective and well-organised as donor-funded market information systems. Examples of international donor agencies which have initiated and financially supported agricultural MIS initiatives in Malawi include USAID, ACE, and ASI (DAES, 2013).

International donor agencies influenced and promoted the establishment of agricultural market information systems in many other Sub-Saharan African countries. In Ghana, for example, a successful agricultural MIS initiative called Esoko (meaning markets in Swahili) was financially supported by USAID in the initial stages (in 2006) of its establishment. In fact, USAID extended the Esoko operations to five other countries in West Africa, namely Benin, Burkina Faso, Mali, Nigeria, and Senegal, through a project called Market Information Systems and Trader's Organisations of West Africa (MISTOWA) (David-West, 2010). Other Sub-Saharan African countries with agricultural MIS initiatives supported by either local or international donor organisations include Rwanda, Kenya, Tanzania, Zambia and Mozambique (Akinyemi, 2013; Mele, 2014).

\section{Agricultural Market Information Systems in Uganda: Successes and Challenges}

Soon after adopting the agricultural market liberalisation policies in the early 1990s, Uganda established a government-run market information service with funding from FAO (Robbins, 2000). Since then there have been so many agricultural MIS initiatives in Uganda mostly financially 
supported by the goverment and donor agencies (both local and international ones). One of the successful agricultural MIS projects once established in Uganda is called African Farm Radio Research Initiative (AFRRI) which operated from 2007 to 2010 (Huggins-Rao, 2011). Funding of AFRRI came from Bill and Melinda Gates Foundation, and the project operated in five African countries: Ghana, Malawi, Mali,Tanzania, and Uganda. The project used radio as the medium for disseminating agriculture-related information to farmers mostly located in rural areas of the five chosen countries. In Uganda, the project worked in partnership with Mega FM radio station located in Gulu, nothern Uganda.

As part of a MIS project evaluation exercise, AFRRI conducted interviews reported by HugginsRao (2011) involving farmers and other stakeholders. The interviews indicate that there are a number of success stories associated with the operation of AFRRI MIS radio project in Uganda. The following are some of the success stories:

- Farmer's income earned from sales of farm produce increased due to accessing markets announced by AFRRI MIS radio programs that offered higher prices for their commodities. Some farmers used the income to build houses and educate their children in better schools.

- Some farmers planted new types of crops, which fetched higher prices at the markets, after obtaining information about such crops from the MIS radio programs.

- The MIS radio programs helped some farmers to acquire knowledge of food preservation and storage.

- Some farmers organised themselves in groups and put their produce together to create commodity quantities which were large enough to convince buyers, through the MIS radio programs, to come to the farmers' locations. By doing this, the farmers avoided bad roads and high transport costs.

- The MIS radio programs linked some farmers directly to buyers, and this reduced the intervention of middle men; hence, the farmers were able to earn more income.

The operations of agricultural MIS projects in Uganda have been facing a myriad of challenges just like in many other Sub-Saharan African countries. Some of the problems associated with agricultural MIS initiatives in Uganda, including the AFRRI project, are as follows:

- Discontinuation of MIS projects when the period specified by the project donors is over. This leaves the beneficiaries of the services in suspense, and usually without a reliable alternative source of the information they used to have.

- High illiteracy level of farmers which makes it difficult for them to fully utilise the services offered by ICT-based agricultural MIS initiatives.

- Limited access to ICT facilities (e.g. PC and Internet connectivity) due to low-income levels of the target group, who are mostly smallholder farmers located in rural areas.

\section{Agricultural Market Information Systems in Malawi: Successes and Challenges}

Currently, almost all agricultural MIS initiatives operating in Malawi targeting smallholder farmers were initiated by international donor agencies. One of the successful agricultural MIS projects in Malawi was funded by a donor agency called Market Linkages Initiative (MLI). Operations of the MLI project included collection of market information from thirteen key markets and distribution of the information to about 4,000 smallholder farmers (DAES, 2013). Another donor agency which financially supports agricultural MIS initiatives in Malawi is ACE, which uses radio and the SMS mobile phone technology for disseminating market information to smallholder farmers. One of the agricultural MIS projects in Malawi is jointly run by ASI and the Department of Agriculture Extension Services (DAES). This agricultural MIS project uses the SMS mobile phone technology for dissemination of agriculture extension messages to smallholder farmers and government extension workers (DAES, 2013).

The main successes of agricultural MIS operations in Malawi are summarised as follows:

- The target group (i.e. smallholder farmers) of the MIS projects claim that their income from sales of farm produce has increased due to making informed decisions when selling their commodities to traders. 
- Some farmers have learned how to protect their crops against pest outbreaks through agricultural MIS projects.

- Agricultural MIS initiatives have enabled some farmers to find buyers directly without involvement of the middle men; therefore, this has helped to improve the farmers' income.

Being a developing nation, Malawi has a number of challenges which prevent full utilisation of the services offered by agricultural MIS initiatives that rely on ICT for service delivery. Some of the challenges are as follows:

- Few farmers, located in the rural areas where most of the agricultural production takes place, have mobile phones and access to Internet facilities; hence, there is usually little participation from target groups (usually rural smallholder farmers) in ICT-based agricultural MIS initiatives.

- Most smallholder farmers are illiterate and therefore they cannot fully exploit the text-based services offered by ICT-based agricultural MIS initiatives.

- Most agricultural MIS projects are discontinued once the duration specified by the project sponsors is over. This leaves the beneficiaries without a service which they used to have.

\section{Access to Telecommunications Services in Uganda and Malawi}

Presented in this section is a comparison of the degree or extent of access to telecommunications services between Uganda and Malawi. The inclusion of Belgium in the comparison is intended to give an idea on the availability of telecommunications services in a developed country. Belgium's level of availability of telecommunications services can be regarded as the ultimate goal for developing countries such as Uganda and Malawi to achieve.

Table 1 shows two important economic indicators related to telecommunications services, namely mobile-cellular subscriptions and individuals using the Internet, for Malawi, Uganda and Belgium in 2013 (UNSD, 2016). Also shown in Table 1 are Gross Domestic Product (GDP) and GDP per capita, which in one way or the other influence the availabilty of telecommunications services in any country.

Table 1 Telecommunications-related economic indicators for Malawi, Uganda and Belgium

\begin{tabular}{|l|l|l|l|}
\hline $\begin{array}{l}\text { Economic indicators } \\
\text { (2013) }\end{array}$ & $\begin{array}{l}\text { Country: } \\
\text { Malawi }\end{array}$ & Uganda & Belgium \\
\hline Surface area $\left(\mathrm{km}^{2}\right)^{*}$ & 118,484 & 241,550 & 30,528 \\
\hline Population* & $16,829,000$ & $38,845,000$ & $11,144,000$ \\
\hline GDP (US\$) & $5,146,000,000$ & $26,444,000,000$ & $524,806,000,000$ \\
\hline GDP per capita (US\$) & 314.5 & 703.7 & $47,260.7$ \\
\hline $\begin{array}{l}\text { Mobile-cellular } \\
\text { subscriptions (per 100 } \\
\text { inhabitants) }\end{array}$ & 32.3 & 44.1 & 110.9 \\
\hline $\begin{array}{l}\text { Individuals using the } \\
\text { Internet (\%) }\end{array}$ & 5.4 & 16.2 & 82.2 \\
\hline
\end{tabular}

Note: Table entries in asterisks (i.e. ${ }^{*}$ ) are not economic indicators Data Source: United Nations Statistics Division (UNSD, 2016)

The table indicates that in 2013 Uganda, with a mobile phone subscription rate of $44.1 \%$, was ahead of Malawi, which had 32.3\% of its population subscribing to mobile phone services. Uganda was not only ahead of Malawi in terms of the mobile phone subscription rate but also in terms of the Internet user rate. In fact, in the case of Internet user rate, Uganda was significantly ahead of Malawi with Uganda's Internet user rate of $16.2 \%$ being three times that of Malawi which was $5.4 \%$. 
However, the availability of telecommunications services in both Uganda and Malawi was very much behind that of Belgium.

Figures 1 and 2 indicate some trends in the level of access to mobile phone services and the Internet, respectively, from the year 2005 to 2013 in Malawi, Uganda, and Belgium. In Figure 1, we notice that Uganda is ahead of Malawi in cellular phone subscriptions in all the three years under consideration. In 2010, mobile phone subscription rate in Uganda was 37.7\% while in Malawi it was $20.8 \%$; this means that the difference was $16.9 \%$ (i.e. $37.7 \%-20.8 \%=16.9 \%$ ). In the year 2013 , we see that the difference in mobile phone subscriptions between the two countries is $11.8 \%$ (i.e. $44.1 \%$ (Uganda) $-32.3 \%$ (Malawi) $=11.8 \%$ ); this means that in 2013 Malawi managed to significantly reduce the difference. One can only hope that Malawi continued to narrow the difference in the subsequent years.

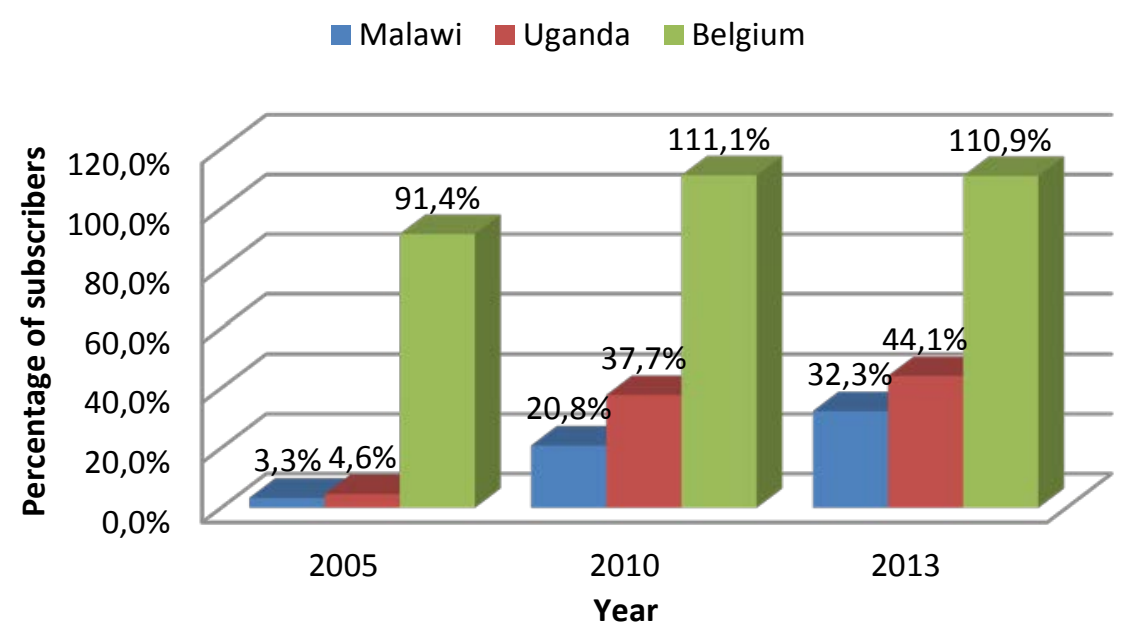

Figure 1 Mobile phone subscriptions in Malawi, Uganda and Belgium

Data Source: United Nations Statistics Division (UNSD, 2016)

In Figure 2, we see that Uganda is also ahead of Malawi in Internet access in all the three years considered: 2005, 2010 and 2013. Between 2005 and 2010, Uganda made a jump of 10.8\% (i.e. 12.5\% $-1.7 \%=10.8 \%$ ) which is much higher than that made by Malawi, which is $1.9 \%$ (i.e. $2.3 \%-0.4 \%=$ 1.9\%), within the same period of time. However, in the years between 2010 and 2013, the jump made by Uganda (i.e. $16.2 \%-12.5 \%=3.7 \%$ ) even though it was higher than that of Malawi (i.e. $5.4 \%$ $2.3 \%=3.1 \%$ ) the difference between them is very small (i.e. $3.7 \%-3.1 \%=0.6 \%$ ). This means that between 2010 and 2013, Malawi managed to improve its Internet access at a rate which is relatively close to that of Uganda.

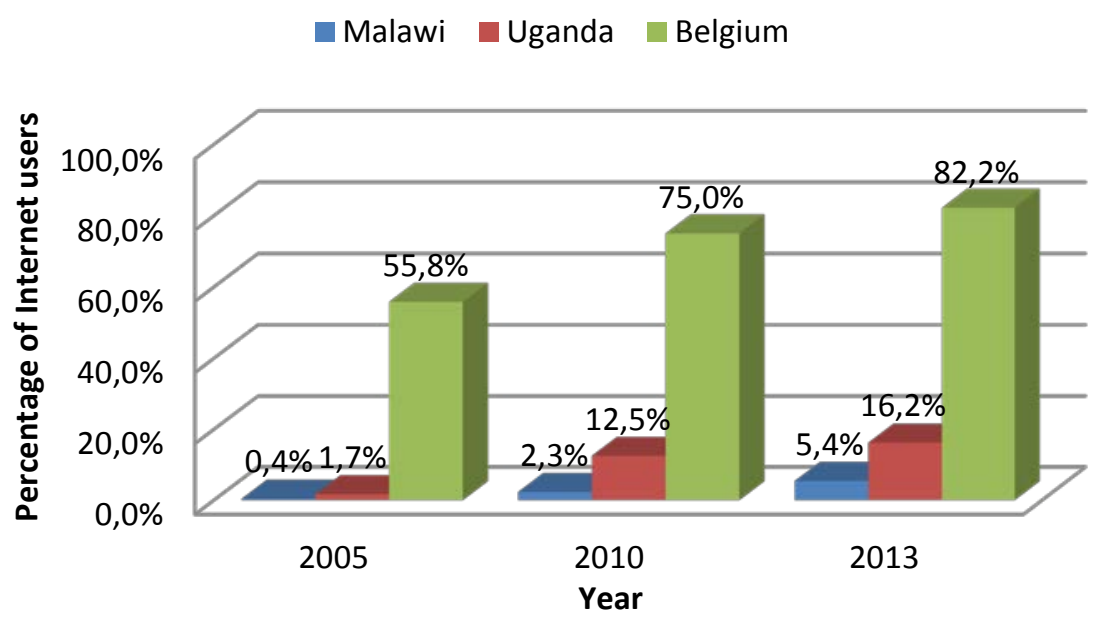


Figure 2 Internet users in Malawi, Uganda and Belgium

Data Source: United Nations Statistics Division (UNSD, 2016)

Based on the graphs shown in Figures 1 and 2, we make two important observations. First, even though both Uganda and Malawi are developing nations in Sub-Saharan Africa, the percentage of the population of Uganda that has access to telecommunications services (i.e. mobile phone services and Internet access) is slightly higher than that of Malawi. This implies that any agricultural MIS initiative that relies on ICT for its service delivery is more likely to succeed in Uganda than in Malawi. The second observation is that both Uganda and Malawi are very much behind Belgium in the provision of telecommunications services. Hence, both Uganda and Malawi need to invest more in ICT facilities in order to provide telecommunications services at a level comparable to that of developed nations.

\section{Discussion}

We discuss mainly the performance of the agricultural MIS initiatives in the two countries in question, namely Uganda and Malawi. The discussion focuses on three areas: (1) the potential of incorporating ICT facilities, (2) the sustainability of agricultural MIS operations, and (3) the impact of agricultural MIS initiatives on the economies of the two countries under consideration.

\subsection{Potential of ICT Usage in Agricultural MIS Initiatives}

Agricultural MIS initiatives discussed in this paper are classified into three categories: mobile phone-based, Internet-based, and radio-based agricultural MIS initiatives. As indicated in Table 2, prepared based on the data shown in Table 1, both Uganda (with mobile phone subscriptions at $44.1 \%$ ) and Malawi (with mobile phone subscriptions at 32.3\%) have, in general or theoretically, a moderate potential of utilising agricultural MIS projects that rely on the mobile phone technology. Considering that the figures of $44.1 \%$ (for Uganda) and 32.3\% (for Malawi) apply to everybody in a population, the number of low-income smallholder farmers that have access to mobile phones in both countries is likely to be relatively very small. Hence, mobile phone-based agricultural MIS initiatives targeting low-income smallholder farmers in the two countries are likely to operate with struggles.

Table 2 Comparison of the potential of ICT usage in MIS initiatives in Uganda and Malawi in 2013

\begin{tabular}{|l|l|l|}
\hline ICT-based MIS initiative & $\begin{array}{l}\text { Country: } \\
\text { Uganda }\end{array}$ & Malawi \\
\hline Mobile phone-based & $\begin{array}{l}\text { Possibility of moderate usage } \\
\text { since mobile phone } \\
\text { subscriptions were at 44.1\%. }\end{array}$ & $\begin{array}{l}\text { Usage likely to be fairly } \\
\text { moderate since mobile phone } \\
\text { subscriptions were at 32.3\%. }\end{array}$ \\
\hline Internet-based & $\begin{array}{l}\text { Possibility of some usage since } \\
16.2 \% \text { of the population had } \\
\text { Internet access. }\end{array}$ & $\begin{array}{l}\text { Almost negligible usage } \\
\text { since only 5.4\% of the } \\
\text { population had Internet } \\
\text { access. }\end{array}$ \\
\hline Radio-based (2011)* & $\begin{array}{l}\text { Usage likely to be high since } \\
86 \% \text { of the population had } \\
\text { access to radio sets. }\end{array}$ & $\begin{array}{l}\text { High usage expected since } \\
75 \% \text { of the population had } \\
\text { access to radio sets. }\end{array}$ \\
\hline
\end{tabular}

Note: Data source is United Nations Statistics Division (UNSD, 2016) as in Table 1

Data source for entries in asterisks (i.e. *) is a report by Huggins-Rao (2011)

In general, an agricultural MIS project that solely depends on the Internet for its service delivery and targets low-income smallholder farmers is likely to fail to meet its objects in both Uganda (with Internet user rate at 16.2\%) and Malawi (with Internet user rate at 5.4\%). While establishing such a 
MIS project in Uganda may have at least a small probability of survival, operating such a project in Malawi is likely to be a total failure right from the beginning.

We see in Table 2 that a large portion of the population of both Uganda (with $86 \%$ of the population having access to radio sets) and Malawi (with $75 \%$ of the population having access to radio sets) has access to radio sets. Therefore, it is likely that most of the low-income smallholder farmers in both countries can access radio services. This deduction leads to another deduction that establishing a radio-based agricultural MIS initiative that targets smallholder farmers in both countries has a high probability of succeeding. This explains why radio-based agricultural MIS projects are operating successfully in Malawi at the moment. In fact, most of the agricultural MIS initiatives that are currently operating in Malawi use a hybrid approach in which a radio-based technique is combined with a mobile phone-based technique to come up with something like a phone-in radio MIS program through which listeners who are usually stakeholders in the agricultural value chain discuss issues affecting their activities. However, since mobile phone subscription rate in Malawi was at $32.3 \%$ in 2013, it means that not all low-income smallholder farmers participate in such a phone-in radio MIS program.

\subsection{Sustainability of Agricultural MIS Operations}

Almost everybody in the agricultural value chain gets disappointed when they see an agricultural MIS project coming to an end simply due to lack of funds to maintain its operations. Unfortunately, this is what happens with most of the donor-financed agricultural MIS initiatives in Sub-Saharan African countries such as Uganda and Malawi.

Most of the agricultural MIS initiatives which once operated in Uganda were in one way or the other financially supported by donor agencies (both local and international ones). For example, when the government established an agricultural MIS project in the early 1990s, FAO financially supported the operations of the project. Later in 1993, USAID took over the funding of the project (Robbins, 2000). The project came to an end in 1999; it is likely that the project was discontinued due to sponsorship problems. Currently, there are a number of donor-funded agricultural MIS initiatives operating in Uganda. Unless such MIS initiatives are self-financing, sustainability of their operations cannot be guaranteed.

All agricultural MIS projects in Malawi targeting smallholder farmers are either donor-funded or government-funded. ACE and ASI are examples of the donor agencies which financially support operations of agricultural MIS initiatives in Malawi (DAES, 2013). One of the problems of donorfunded projects is that they operate as pilot projects which cover only a small targeted area. Hence, most of the smallholder farmers in Malawi have no access to services offered by such projects. By having self-financing agricultural MIS projects, Malawi will not only solve the problem of service sustainability but also increase coverage area which at the moment is limited by the sponsorship provided by donors.

\subsection{Impact of Agricultural MIS Initiatives on National Economies}

While it could have been more desirable to present a quantitative analysis of the impact of the agricultural MIS initiatives considered in this review on the national economies involved, the belief in this analysis is that the success stories of the agricultural MIS projects presented in this paper show in one way or the other the positive impact of such projects on the national economies involved. For example, since smallholder farmers are able to increase their income from sales of farm produce by finding better markets for their produce through agricultural MIS projects, the farmers are motivated to increase their agricultural production. Obviously, an increase in agricultural production addresses food security problems and improves the national economies in general.

\section{Recommendations for MIS Initiative Improvement in Malawi and Uganda}

Recommendations are presented here as the final product of this review exercise. The recommendations apply to both Malawi and Uganda, and these are as follows: 
- There is a need to find a way of increasing access to mobile phone services especially by lowincome small holder farmers for them to utilise ICT-based agricultural MIS projects fully.

- Increase of Internet access by farmers is needed for them to conveniently access information at their own time unlike in a radio program which broadcasts information at fixed times.

- Participation of the private sector should be promoted since it has the capability of establishing self-financing MIS projects that are economically sustainable.

\section{Concluding Remarks}

The comparative analysis of the potential of incorporating ICT in agricultural MIS initiatives operating in Uganda and Malawi is based on the data on economic indicators related to telecommunications services provided by the statistics division of the United Nations (UNSD, 2016). The analysis has revealed the extent to which Uganda and Malawi can successfully offer ICT-based agricultural market information services at the moment. Both Uganda and Malawi need significant improvement in the provision of ICT facilities to low-income smallholder farmers. Since deploying such facilities on a large scale is usually expensive, both Uganda and Malawi will still need the support of international donor agencies in all their future efforts aimed at improving agricultural MIS initiatives.

\section{References}

Akinyemi, D. T. (2013). Rwanda’s e-soko: accessing information technologies in Rwanda for economic development and poverty reduction. Proceedings of Global Geospatial Conference 2013, Addis Ababa, Ethiopia, 4 - 8 November 2013.

Alderman, H. \& Shively, G. (1996). Economic reform and food prices: evidence from markets in Ghana, Elsevier Ltd, World Development, Vol. 24, Issue 3, pages 521 - 534. doi: 10.1016/0305-750X(95)00146-4

ASI, ( 2015). Malawi Technology for Extension to Smallholders (TEXTS). Retrieved August 8, 2015, from http://www.asintl.org/ASI-TEXTS-Brochure.pdf

CTA (2000). Technical consultation on the development of market information services (MIS) for small operators in the agricultural sectors of ACP countries. Proceedings of a CTA workshop, Wageningen, The Netherlands, 30 - 31 October 2000. Retrieved November 20, 2015, from http://www.anancy.net/documents/file_en/8023_Technical_consultation_on_the_development_of_market.pdf

DAES, (2013). Technology for Extension to Smallholders (TEXTS, Training Manual for Mobile Agriculture Extension, Department of Agriculture Extension Services (DAES) of Malawi Government and Agribusiness Systems International (ASI).

David-West, O. (2010). Growing Inclusive Markets, Esoko Networks: Facilitating Agriculture through technology. Case Study Report by UNDP. Retrieved May 12, 2015, from http://growinginclusivemarkets.com/media/cases/Ghana_Esoko_2010.pdf

Huggins-Rao, S. (2011). Marketing on the airwaves: Marketing Information Service (MIS) and radio. Evaluation report, Farm Radio International \& African Farm Radio Research Initiative. Retrieved December 1, 2015, from http://www.farmradio.org/wp-content/uploads/Marketing-on-the-airwavess.pdf

Islam, M. S. \& Gronlund, A. (2010). Agricultural market information services (AMIS) in the least developed countries (LDCs): nature, scopes, and challenges. Lecture notes in computer science, Springer, pp. $109-120$. Retrieved November 21, 2015, from https://hal.inria.fr/hal-01059170/document. doi: 10.1007/978-3-64214799-9_10

Jayne, T. S. \& Jones, S. (1997). Food marketing and pricing policy in Eastern and Southern Africa: A survey. Elsevier, World Development, vol. 25, issue 9, pages 1505 - 1527. doi: 10.1016/S0305-750X(97)00049-1

Kherallah, M., Delgado, C., Gabre-Madhin, E., Minot, N. \& Johson, M. (2000). The Road Half Traveled: Agricultural Market Reform in Sub-Saharan Africa. Food Policy Report, International Food Policy Research Institute, Washington D.C.

Magesa, M., Michael, J. \& Ko, J. (2014). Agricultural Market Information Services in Developing Countries: A Review. ACSIJ Advances in Computer Science: an International Journal, Vol. 3, Issue 3, No. 9, ISSN:23225157. 
Mele, P. (2014). Dialing up the future: How mobile-based services are changing the way we manage agriculture. Esoko Kenya Brochure by Catholic Relief Services (CRS).

Nyairo, N. (2011). Impact of agricultural market liberalization on food security in developing countries: a comparative study of Kenya and Zambia, Academic dissertation, Publication Nr 50, Agricultural Policy 122p, University of Helsinki. Retrieved December 1, 2015, from http://www.helsinki.fi/taloustiede/Abs/Pub50.pdf

Robbins, P. (2000). Design of a market information system for small scale producers and traders in three districts of Uganda. Study report, ITTA/Foodnet project, Technical Centre for Agricultural and Rural Cooperation (CTA). Retrieved November 20, 2015, from https://cgspace.cgiar.org/bitstream/handle/10568/63621/ctaworkingdoc_8019.pdf

Robbins, P. (2000-b). Review of market information systems in Botswana, Ethiopia, Ghana, and Zimbabwe. Study report, Technical Centre for Agricultural and Rural Cooperation, CTA, The Netherlands. Retrieved November 20, 2015, from http://www.anancy.net/documents/file_en/982_Review_of_market_information_systems_in_Botswana.pdf

Tollens, E. (2006). Market Information Systems in Sub-Saharan Africa: Challenges and Opportunities. International Association of Agricultural Economists Conference, Poster paper, Gold Coast, Australia, August 12 -18, 2006.

UNSD (2016), UNdata: A World of Information, World Statistics Pocketbook - United Nations Statistics Division. Retrieved March 17, 2016, from http://data.un.org/CountryProfile.aspx?crName $=\{$ malawi,uganda,belgium $\}$.

USAID (2013). An assessment of market information systems in East Africa. Briefing paper, Retrieved August 6, 2015, from http://agrilinks.org/library/assessment-market-information-systems-east-africa. 